\title{
THE CITY MODEL AS A TOOL FOR PARTICIPATORY URBAN PLANNING - A CASE STUDY: THE BILOTTI OPEN AIR MUSEUM OF COSENZA
}

\author{
S. Artese \\ Department of Informatics, Modelling, Electronics and Systems Engineering, University of Calabria, Rende, Italy - \\ serena.artese@unical.it
}

KEY WORDS: Cultural Heritage, City Model, 3D Modelling, Augmented Reality, Multiresolution, Laser scanning,

\begin{abstract}
:
The paper describes the implementation of the 3D city model of the pedestrian area of Cosenza, which in recent years has become the Bilotti Open Air Museum (MAB). For this purpose were used both the data available (regional technical map, city maps, orthophotos) and acquired through several surveys of buildings and "Corso Mazzini" street (photos, topographic measurements, laser scanner point clouds). In addition to the urban scale model, the survey of the statues of the MAB was carried out. By means of data processing, the models of the same statues have been created, that can be used as objects within the city model.

The 3D model of the MAB open air museum has been used to implement a Web-GIS allowing the citizen's participation, understanding and suggestions. The 3D city model is intended as a new tool for urban planning, therefore it has been used both for representing the current situation of the $\mathrm{MAB}$ and for design purposes, by acknowledging suggestions regarding a possible different location of the statues and a new way to enjoy the museum.
\end{abstract}

\section{INTRODUCTION}

An urban open-air museum is a peculiar site, where the works of art are surrounded by buildings; size, shape and textures of constructions and urban furniture contribute to create the museum, which is the fusion of the works of art and of the surrounding architecture. For its modeling, the surveying cannot be limited to the works of art, but it must regard a portion of the city, the streets and the squares, the single buildings and finally the statues. Therefore, a City Model with different Levels of Detail should be realized.

A 3D City Model is a three-dimensional digital representation of an urban environment built by using data obtained from multiple sources, such as stereo aerial imagery, Lidar data from aircraft and, for detailed models, data obtained by close-range acquisitions (photogrammetry, laser scanner). It contains a large number of objects of different classes, so a multi-resolution representation is generally required.

The diffusion of 3D city models is rapidly growing. They are used e.g. for urban planning, facilities management, transportation, energy saving. The increasing use of 3D city models has been facilitated by the improvements to 3D reconstruction methods (Haala and Kada, 2010; Tian et al., 2010). An important rule is also played by City GML, the common standard for the representation and the exchange of 3D city models, allowing the management of data with regard not only to geometric characteristics, but also to topological and semantic aspects (Gröger and Plümer, 2012). 3D City models can be better exploited by using the techniques of Virtual Reality (Burdea and Coiffet, 2003). The potentialities of VR have been foreseen since half a century (Sutherland, 1965) and the applications are countless, also for urban planning (Axford et al., 2007).

The evolution of new sensors, along with the increasing computing power and the evolvement of techniques for the management of very large data sets allows the representation of complex sites. For 3D modeling the most used methodologies are based on image data (Remondino and El-Hakim, 2006) and range data (Beraldin et al., 1997). Classical surveying and GNSS receivers are still used for georeferencing and to obtain control points. Different methodologies are ever more integrated, to take advantage from each technique (Artese et al., 2003; El-Hakim et al., 2004; Remondino et al., 2009).

For the image data, featureless approaches are currently used (Hammoudi and Dornaika, 2011), whilst for range data the classical ICP method (Besl and McKay, 1992; Chen and Medioni, 1992; Zhang, 1994) is still used by the most diffused software (see references from websites).

For the surveying of medium-size objects, like the statues of an open-air museum, it's possible to use Time of Flight (TOF) laser scanner acquisitions, generally integrated by close range scans, obtained by triangulation instruments (Ressl, 2007); if a high accuracy is not required, the use of triangulation instruments can be avoided and the TOF laser scanner can be used for both buildings and statues surveying (Artese et al., 2013).

Hereinafter is described the set up of a multi-source multiresolution 3D city model of the pedestrian zone of Cosenza, Italy, became an open-air museum. The city model has been used to implement a Web-GIS allowing the citizen's participation, understanding and suggestions. The design of a different accommodation of the museum, due to the suggestions received by the citizens in a first test, is shown.

\section{THE BILOTTI OPEN AIR MUSEUM (MAB)}

Sited in southern Italy, Cosenza was known in antiquity as the Athens of Calabria, thanks to its cultural past: the Accademia Cosentina, e.g., was one of the very first academies to be founded in Europe (1511).

The city is located at the confluence of Busento and Crathis rivers, and is surrounded by seven hills. Alaric, king of the Goths, died in 410 in Cosenza and his body, according to legend, was buried under the riverbed of the Busento. The stream was temporarily diverted from its course while a grave was dug wherein the Gothic chief and some of his most precious spoils were interred (Jordanes, 552).

One of the most important artistic emergencies of Cosenza is certainly the Bilotti Open Air Museum (MAB), built in the last few years thanks to the donations of the patron Carlo Bilotti and continued by his brother Enzo. It consists of several sculptures, sited in the pedestrian area of the city, along the 
main road, realized by famous artists of XXth and XXIth centuries (de Chirico, Dalì, Greco, Manzù, Sosno, Consagra). The open air museum has been the subject of an intense debate, still ongoing; this debate also focuses on some aspects that could be addressed with the use of city models and virtual reality. In particular, a different location of the statues, the use of new basements and the creation of zones for the enjoyment of works of art could be efficiently shown through virtual reality, thus providing valuable information.

\section{THE CITY MODEL OF THE MAB: SURVEYING AND MODELING}

The source data available for the realization of the model are the Regional Technical Maps in the scales 1:5.000 and 1:2.000, along with the orthophoto 1:5.000. The volume of the buildings has been obtained by the extrusion of the perimeters drawn in the map.

An airborne LIDAR survey, with a density of $4 \mathrm{pts} / \mathrm{m}^{2}$ has been performed in 2010; the DSM (Figure 1) has been used to extract the geometry of the roofs.

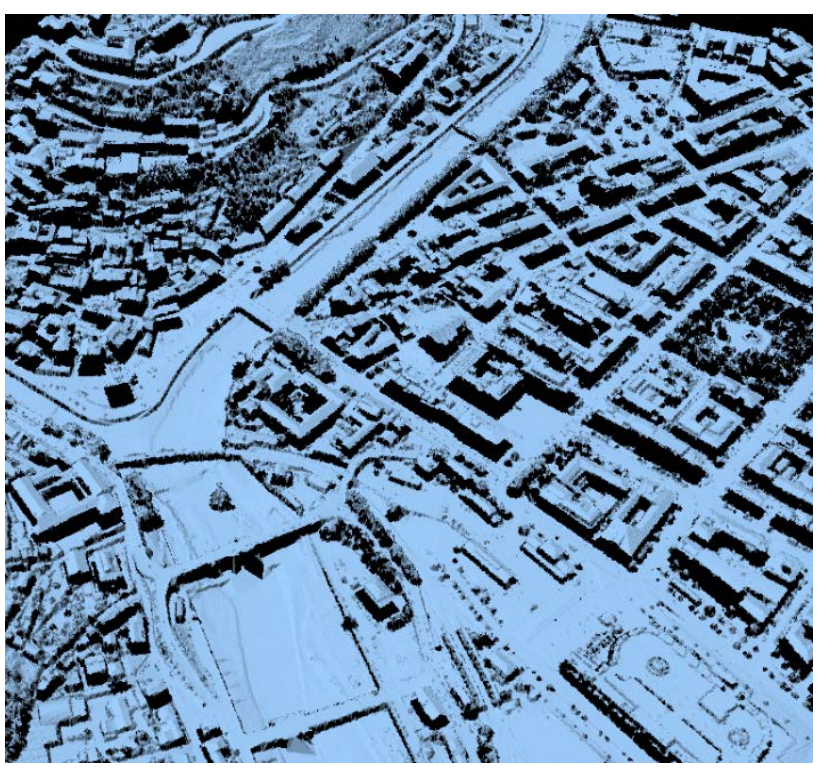

Figure 1. The DSM of Cosenza.

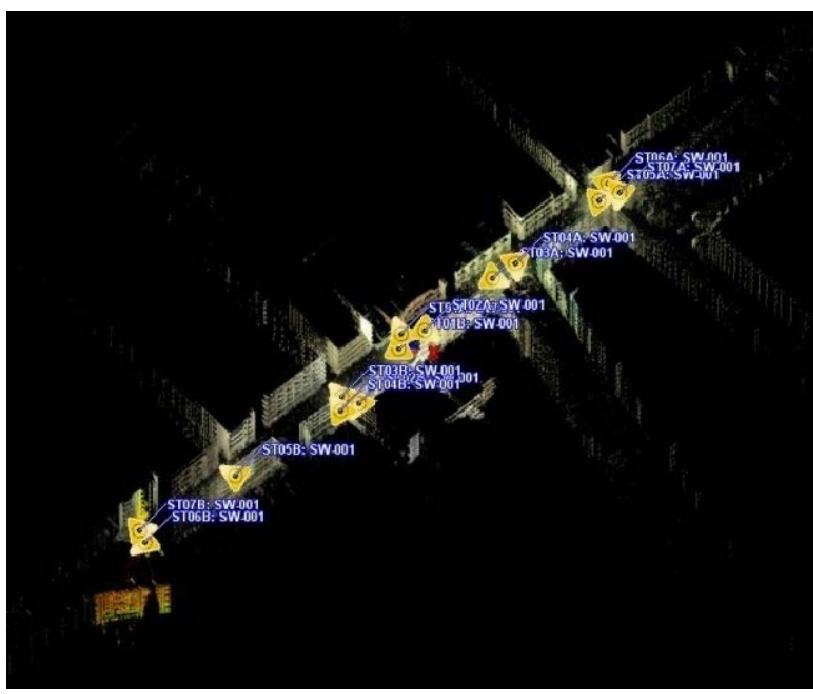

Figure 2. The layout of the TOF Laser Scanner Survey.
The surveying of the MAB open-air museum was carried out in the spring 2011. The pictures of the facades of all buildings in the pedestrian zone were acquired. After the rectifying, the texturing of the buildings has been performed. According with the CityGML classification, an LoD 2 textured city model has been obtained.

For the georeferencing, a GNSS receiver in RTK mode was used and the scans targets were surveyed. By means of the TOF laser scanner Leica Scan Station C10, it was carried out the acquisition of all statues and of the pedestrian zone. Figure 2 shows the point cloud of the facades and the location of the laser scanner acquisitions.

Figure 3 shows a point cloud obtained by the TOF Laser Scanner for the central zone of the MAB; the targets used for the registration of the scans are visible.

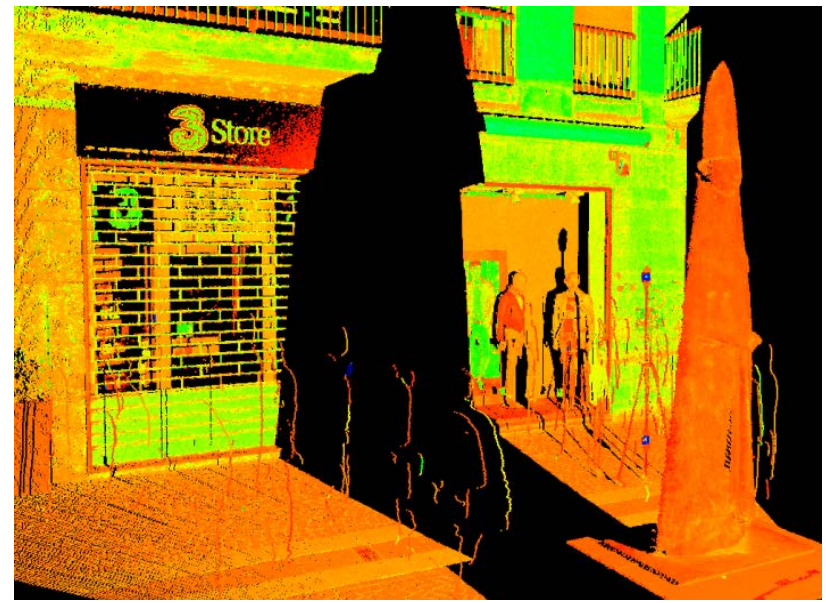

Figure 3. A point cloud obtained by the TOF Laser Scanner.

Some statues of the MAB had been surveyed by using a triangulation scanner Minolta VIVID 300. A comparison between the results obtained by triangulation and TOF laser scanner has been performed for the statue "The Wolf of Sila", which author is Mimmo Rotella. It is characterized by flat surfaces and sharp edges and was realized with green marble. The dimensions (lenght, width and height) are $147 \times 38.5 \times 120$ $\mathrm{cm}$ for the statue and $180 \times 88 \mathrm{x} 17 \mathrm{~cm}$ for the basement.

The purpose of the comparison is to assess whether the loss of information due to the lower accuracy of the TOF laser scanner is acceptable and if it is possible to build, by using a single scan, both models of buildings and statues of the city models, or if it's necessary to use different instruments.

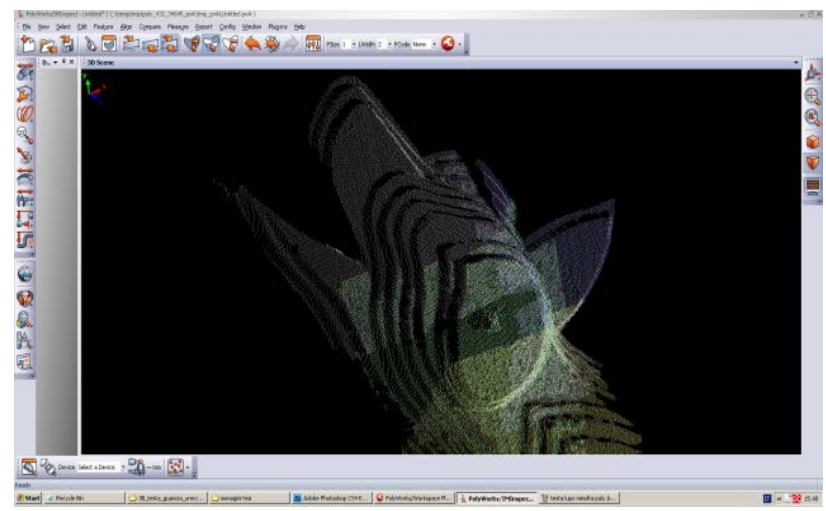

Figure 4. The merge of 5 VIVID 300 scans for the Wolf of Sila. 


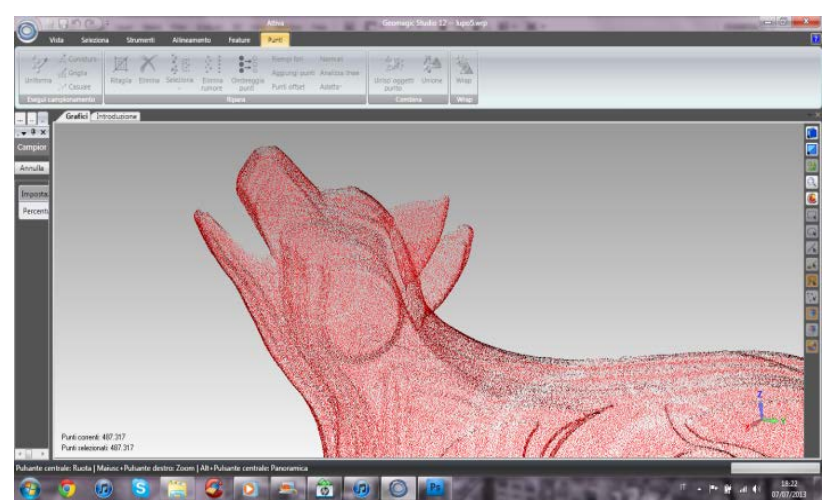

Figure 5. The point cloud of the Wolf of Sila, obtained by a single scan of TOF laser scanner

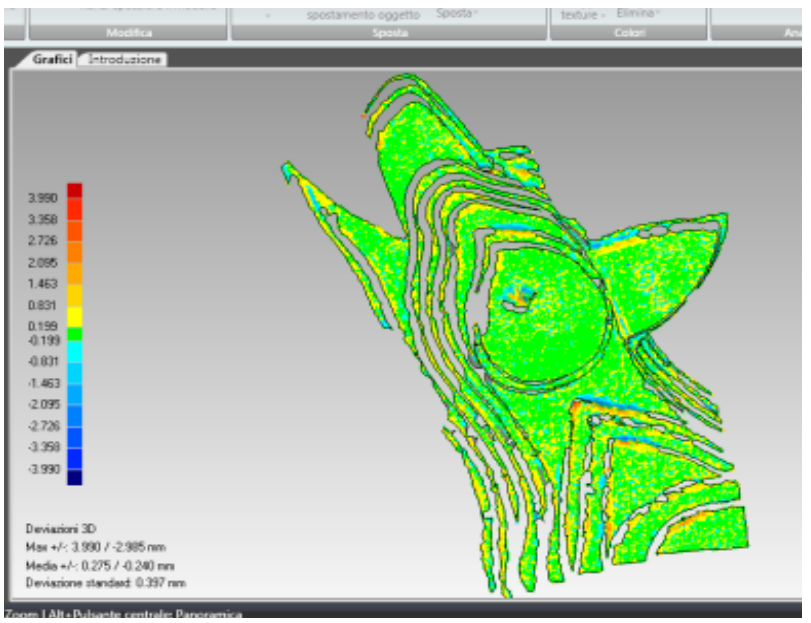

Figure 6. The deviations among the scan points and the model of the Wolf of Sila obtained by 5 aligned scans acquired by using the VIVID 300 scanner.

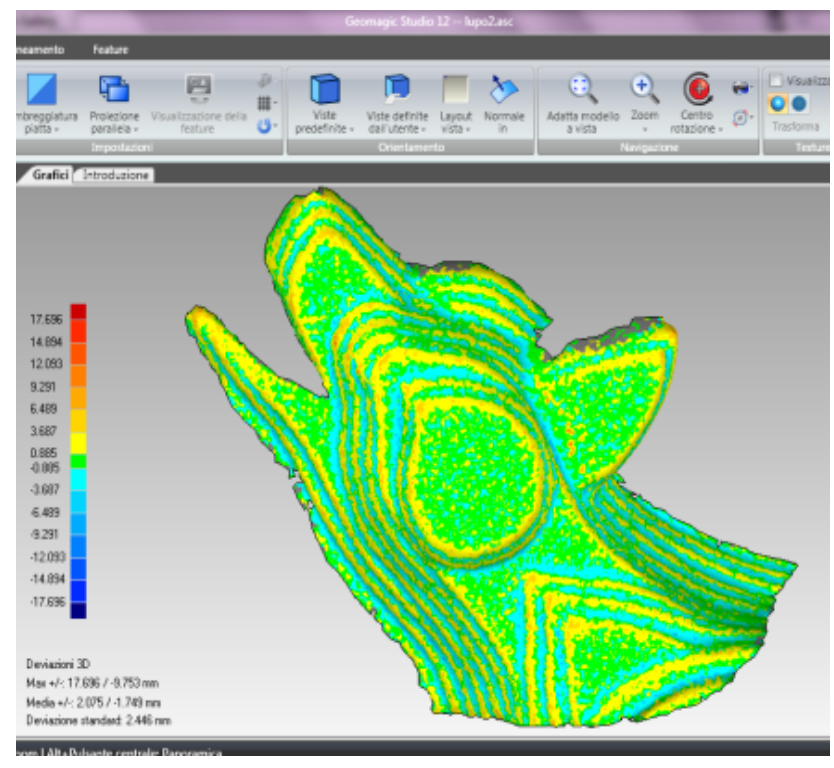

Figure 7. The deviations among the scan points and the model of the Wolf of Sila obtained a single scan acquired by using the Leica C10 ToF laser scanner.

Figure 4 shows the merging of 5 VIVID 300 scans, while figure 5 shows the point cloud obtained by a single scan of the Leica
C10. The statistics given by the Geomagic ${ }^{\circledR}$ software have been used.

The distribution of the deviations among point clouds and models is shown, for the head of the statue The Wolf of Sila, in the figure 6 (triangulation laser scanner, merge of 5 scans) and figure 7 (ToF laser scanner, single scan). A comparison between the numeric results is reported in table 1 . The ratio between the maximum deviations (ToF to Triangulation laser scanner) is about 4 and the ratio between the standard deviations is about 6 ; for the ToF laser scanner, deviations greater than $3 \mathrm{~mm}$ (orange, red and dark blue zones in figure 7) are attained in few points, while the standard deviation is influenced by the smoothing of the sharp edges, due to the automatic procedure. It is possible, of course, to improve the ToF model by using breaklines, but taking into account the value of the standard deviation (less than $3 \mathrm{~mm}$ ) and the goal of the surveying (to create objects to be positioned in the city model), we decided to use the scans obtained by the ToF laser scanner and to use an automatic procedure without further refinements. Therefore the models obtained by TOF laser scanner have been used and transformed into objects to be positioned in the city model, while the survey performed by means of the triangulation scanner has been used for documentation aims. Figure 8 shows a view of the city model with the statue in the present position.

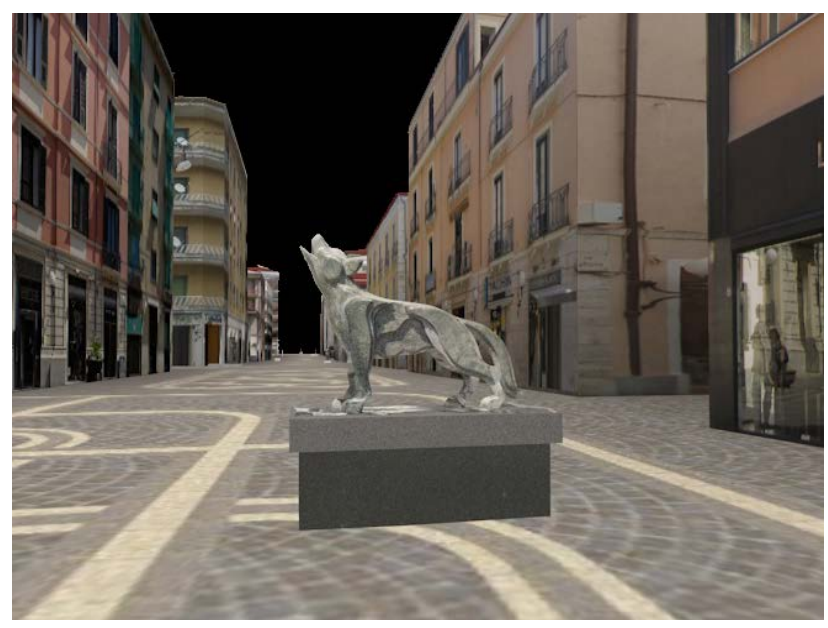

Figure 8. The Wolf of Sila in the present location.

\begin{tabular}{|c|c|c|c|c|c|}
\hline \multirow[b]{2}{*}{ MODEL } & \multicolumn{4}{|c|}{ 3D DEVIATIONS (mm) } & \multirow{2}{*}{\begin{tabular}{|c} 
STANDARD \\
DEVIATION \\
$(\mathrm{mm})$
\end{tabular}} \\
\hline & $\begin{array}{c}\text { Max } \\
\text { positive }\end{array}$ & $\begin{array}{c}\text { Max } \\
\text { negative }\end{array}$ & $\begin{array}{l}\text { Average } \\
\text { positive }\end{array}$ & $\begin{array}{l}\text { Average } \\
\text { negative }\end{array}$ & \\
\hline $\begin{array}{c}\text { VIVID } \\
300 \\
\end{array}$ & 3.99 & -2.99 & 0.28 & -0.24 & 0.40 \\
\hline C 10 & 17.70 & -9.75 & 2.08 & -1.75 & 2.45 \\
\hline
\end{tabular}

Table 1. points-model from the C10 scans, for the head of the Wolf of Sila

To obtain the models of the statues, the software 3D Reshaper ${ }^{\circledR}$ has been used. The typical tasks of model construction (decimation of point clouds, 3D Delaunay triangulation, smoothing, hole filling, Texture Mapping) have been performed. The tasks are shown for the "Head of Medusa", a statue of Giacomo Manzù, in figures 9 to 12.

The result of all activities is a Virtual Reality environment. It consists of the city model and of the models of the statues. 
Several deliverables can be obtained: views of the MAB, 360degree photos, 3D views (anaglyphs, with active or passive glasses), mono and 3d virtual videos, maquettes and models through the use of stereolithography (3D printing).

Figure 13 shows a screenshot of the software TruView, with a partial view of the MAB and the measurement of the height of the de Chirico's statue Hector and Andromache.

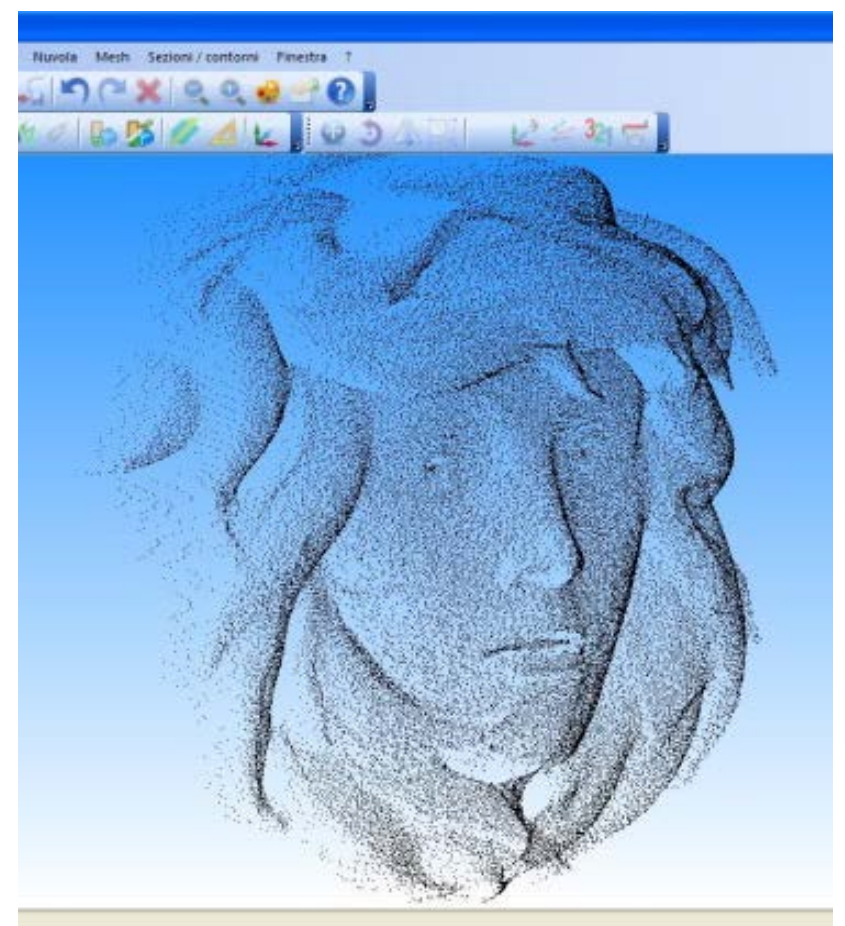

Figure 9. Point cloud of the Head of Medusa.

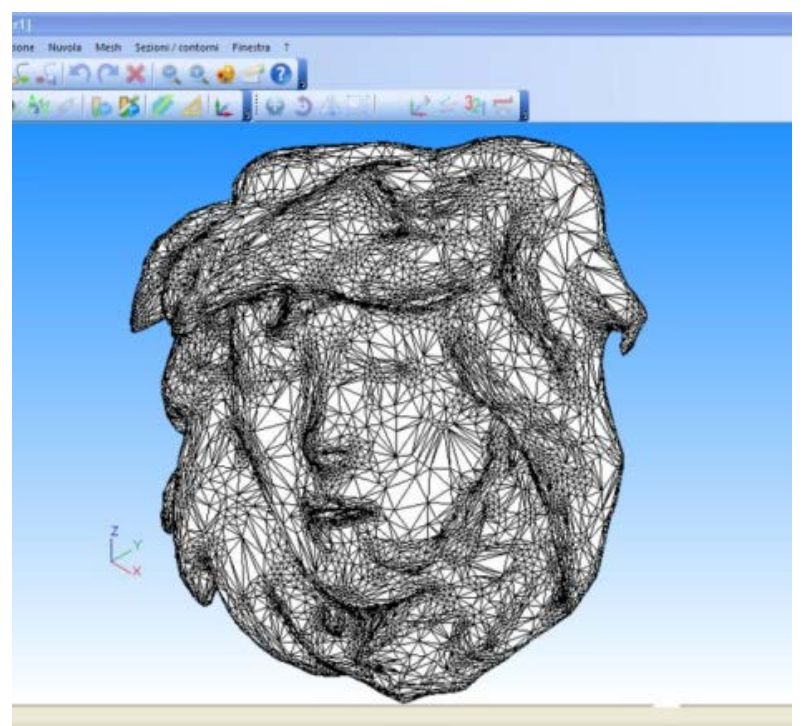

Figure 10. 3D Delaunay triangulation.

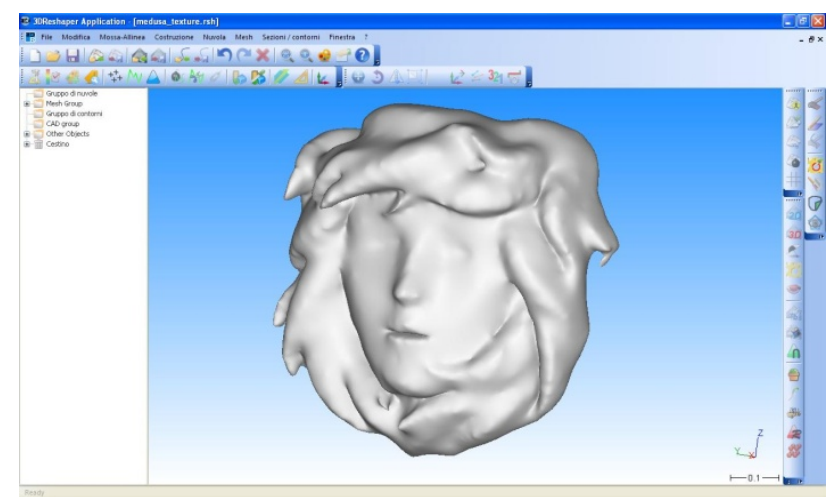

Figure 11. Smoothing.

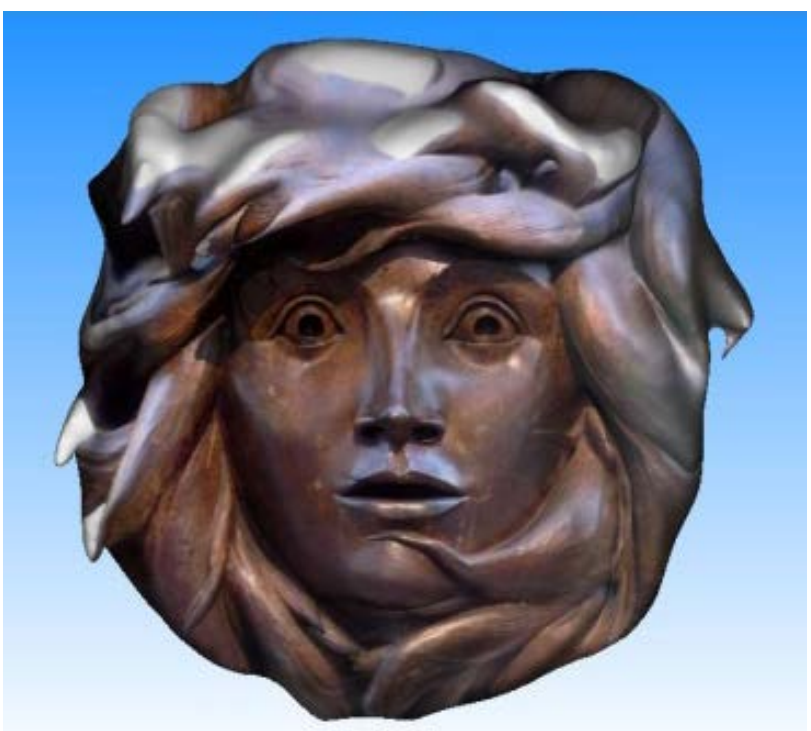

Figure 12.Texture Mapping.

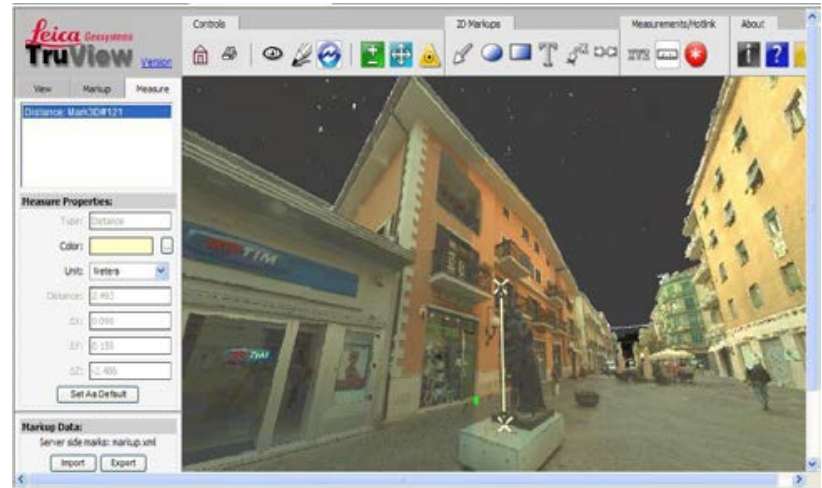

Figure 13. Screenshot of Trueview® software. 


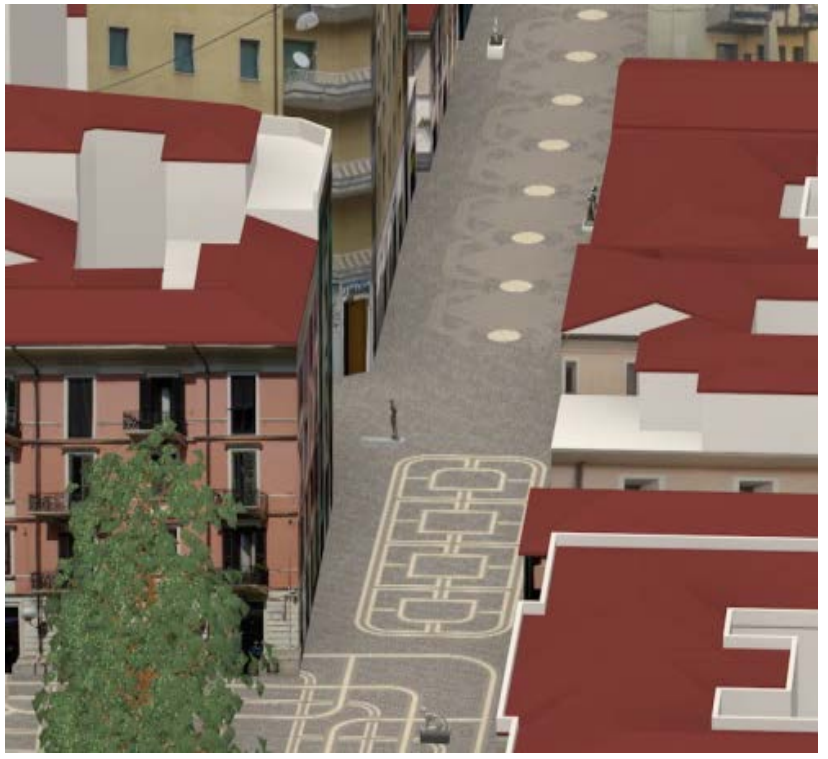

Figure 14 . South view of the city model with the present arrangement of the statues.

Two global views of the open-air museum, with the present arrangement of the statues, are shown in figures 14 and 15. In Figures 16 and 17 we can observe the models of The great Cardinal standing and of Hector and Andromache in the present position.

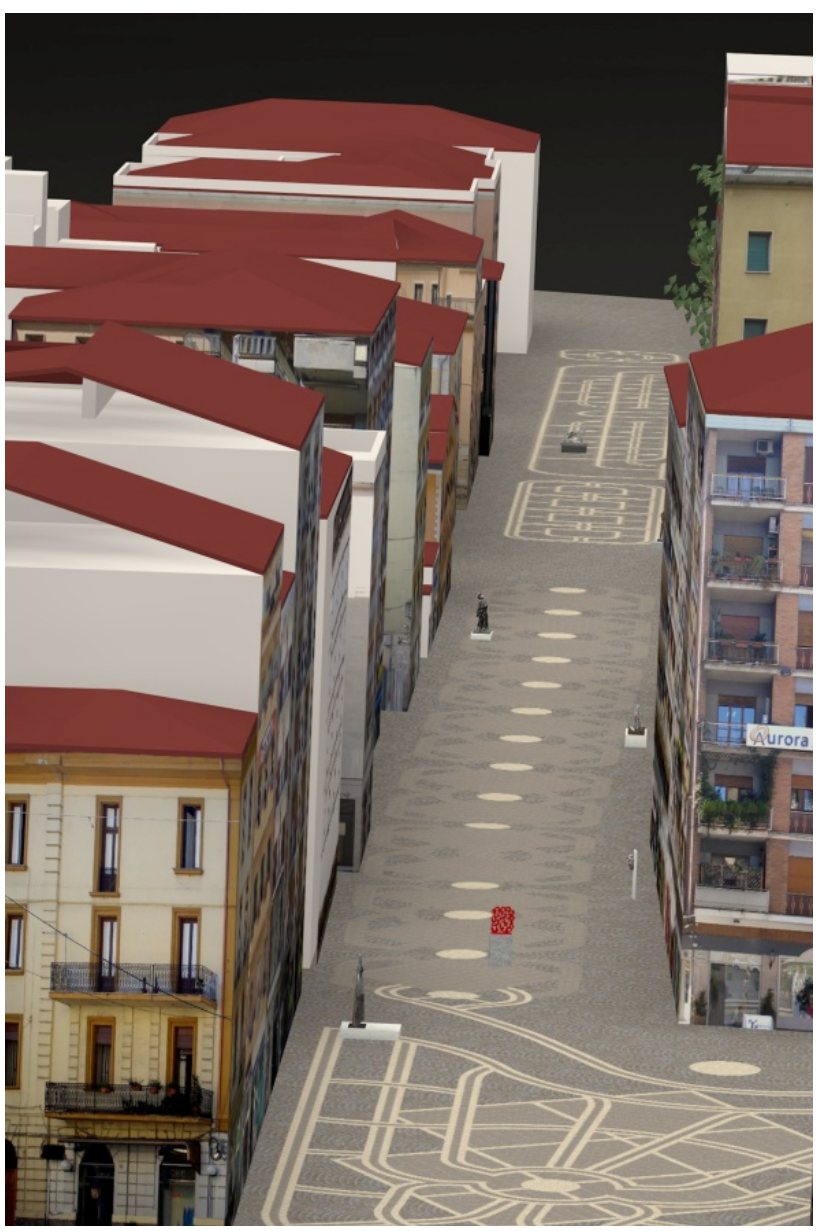

Figure 15. North view of the city model with the present arrangement of the statues.

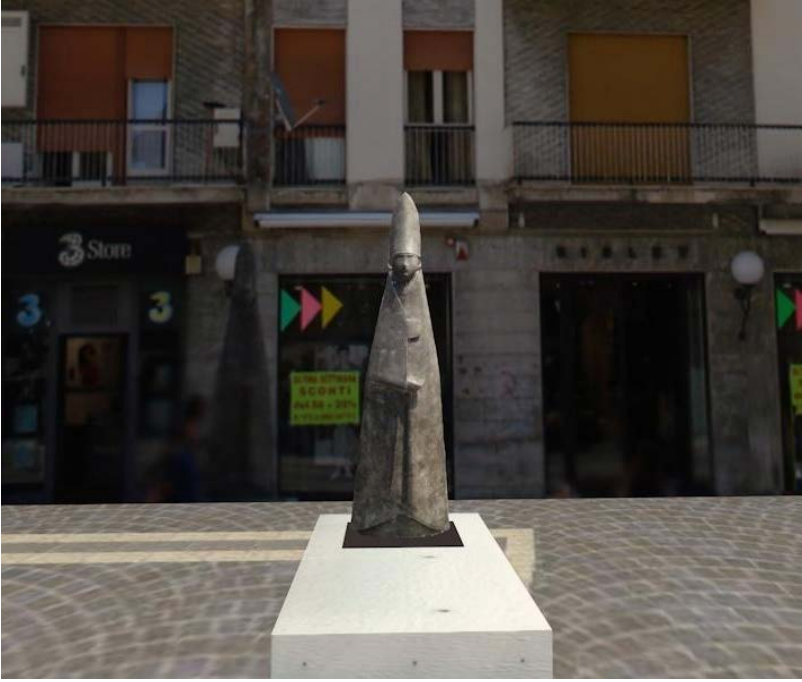

Figure 16. The model of The great Cardinal standing in the present position.

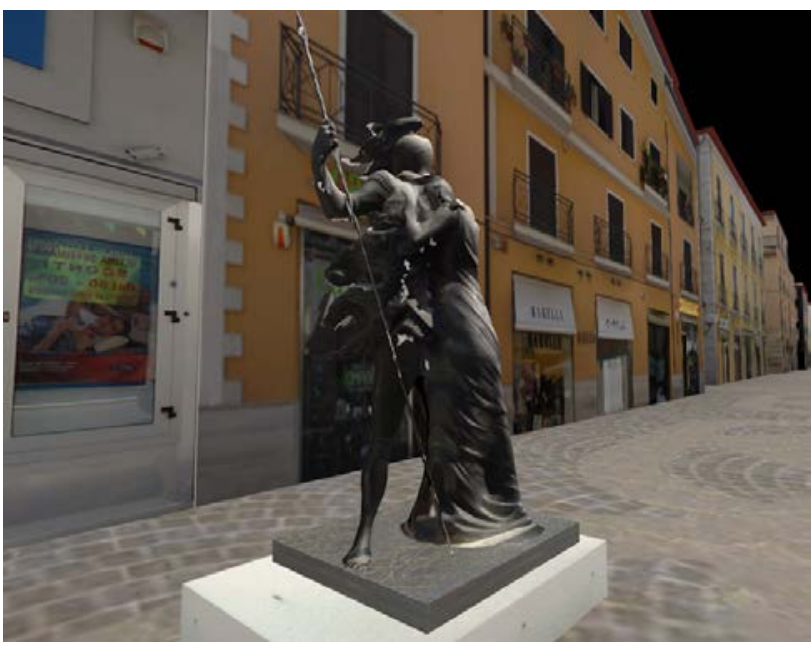

Figure 17. The model of Hector and Andromache in the present position.

\section{A TOOL FOR PARTICIPATORY URBAN PLANNING}

The participation of citizens in urban planning has always considered desirable (Arnstein, 1969) and several methods have been proposed for optimizing the interaction between citizens and planners (Pasetti Monizza et al, 2013; Knapp and Coors, 2008).

Among the several suggested methods, it is certainly remarkable the Planning for Real technique, or PFR (Gibson, 1998). Designed by a team of researchers at the University of Nottingham led by Tony Gibson in the seventies, PFR was widespread in Northern Europe by members of the New Urbanism and is still used. The choices are made at the end of a sort of game, in which the experts act as facilitators, while the inhabitants act as gamers. The first stage involves the construction of a model of the area covered by the plan, the maquette is exposed for a short period, in places frequented by the community, and the citizens will leave on the model post-it with suggestions on actions to be done. After a negotiation phase, designers can make their decisions consciously. It is clear that in this case the use of a semantic 3D city model, 
instead of a maquette or 2D drawings, facilitates understanding by the ordinary citizen, while the information is certainly more effective. Furthermore, the participation is more active, because of the possibility, for the citizen, to verify the effects of some of his proposals.

In our case, the 3D model of the MAB open air museum has been used to implement a Web-GIS. After a login it's possible to propose a different location of the statues and to express opinions and suggestions. The logged people can observe some views of the MAB with the old and the new placing of statues. It's also possible to observe a fly-through, along predetermined paths. Citizens may thus be involved and really participate in a more effective way towards the choices about the future of their city.

In the first experimental phase, although a few people have been involved to test the capabilities of the system, it was confirmed the importance of citizen participation. Along with the suggestions about the location of statues, some interesting prompts have been received regarding the actual fruition of the museum by the disabled people. Following this suggestions, a different arrangement of the statues, based on grouping by author, was simulated; it was also made the open-air museum accessible for blind people through the inclusion of a path consisting of driving elements and the realization of miniature statues.

Figure 18 shows a North view of the city model with the new arrangement of statues. Figures 19 to 23 show some views of the pedestrian zone of the city with the new arrangement of statues and miniatures.

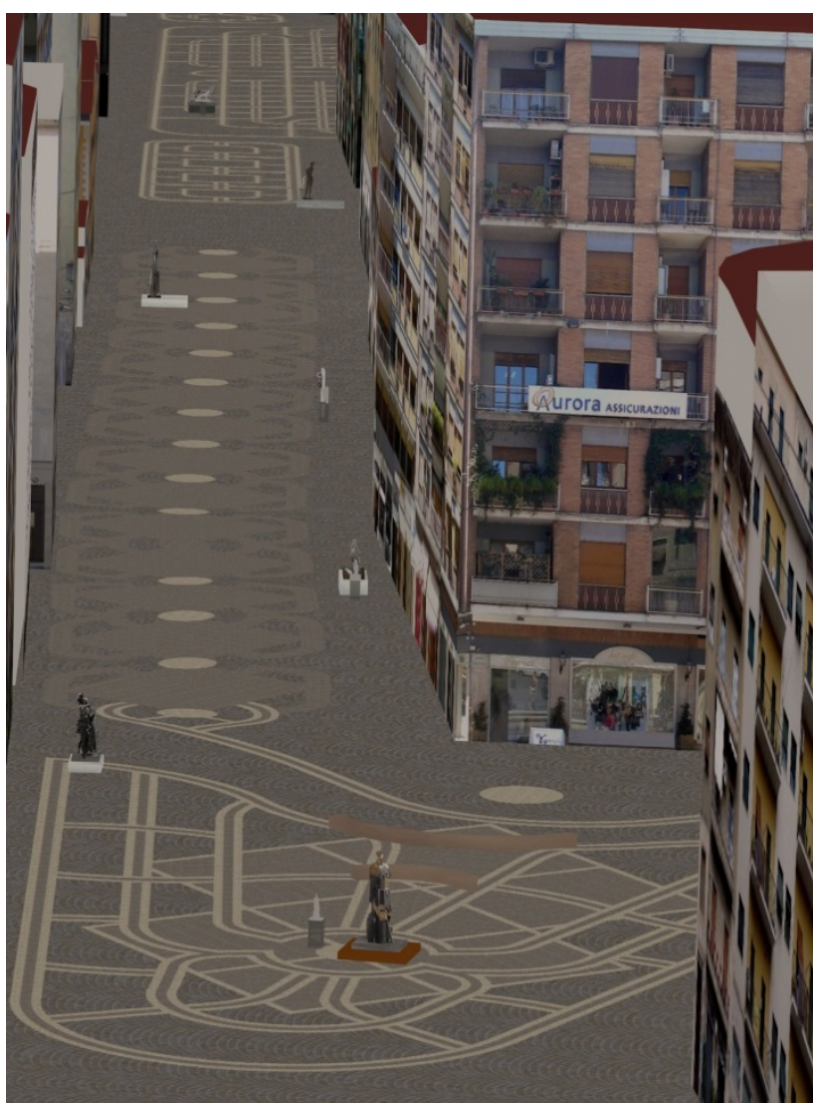

Figure 18. North view of the city model with the new arrangement of statues.

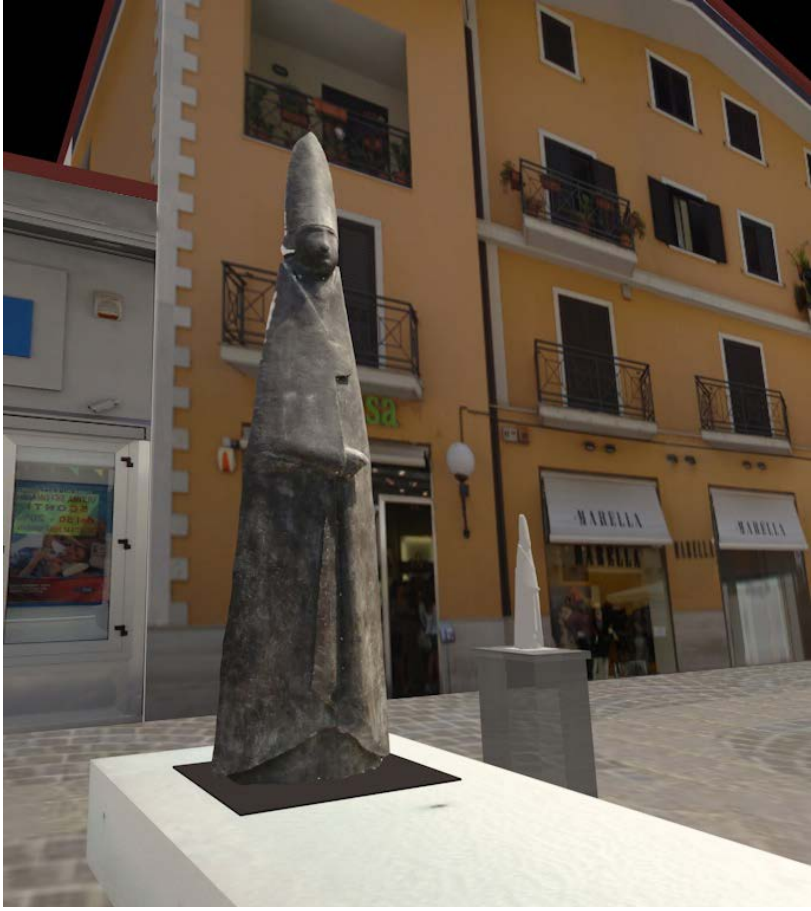

Figure 19. The models of The great Cardinal standing and of the miniature in the new position.

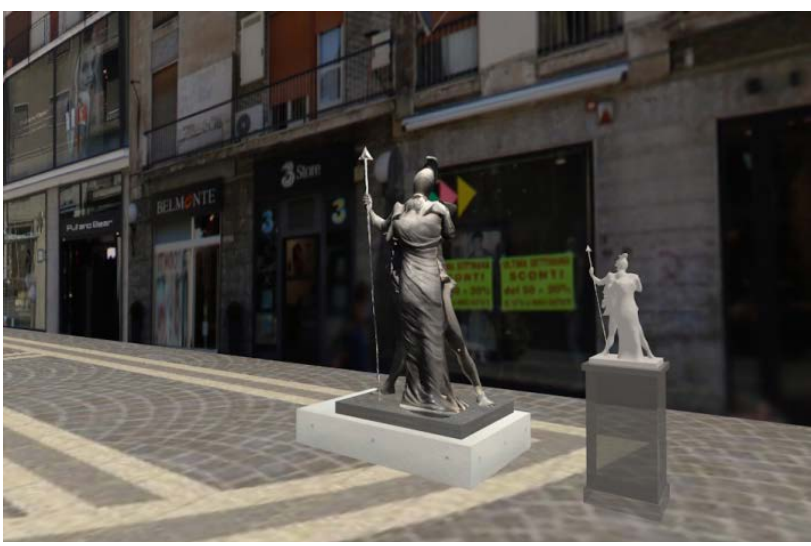

Figure 20. The models of Hector and Andromache and of the miniature in the new location.

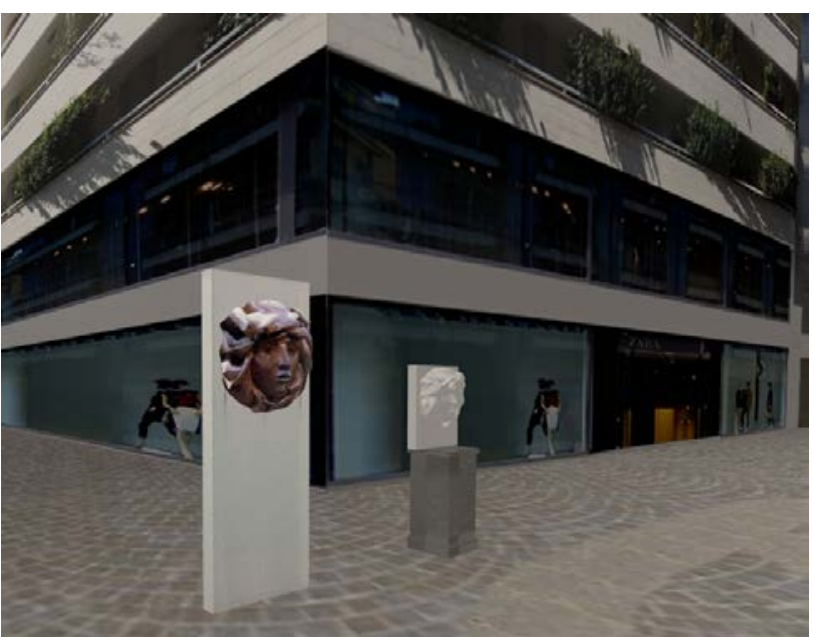

Figure 21. The model of The head of Medusa and of the miniature in the new position. 


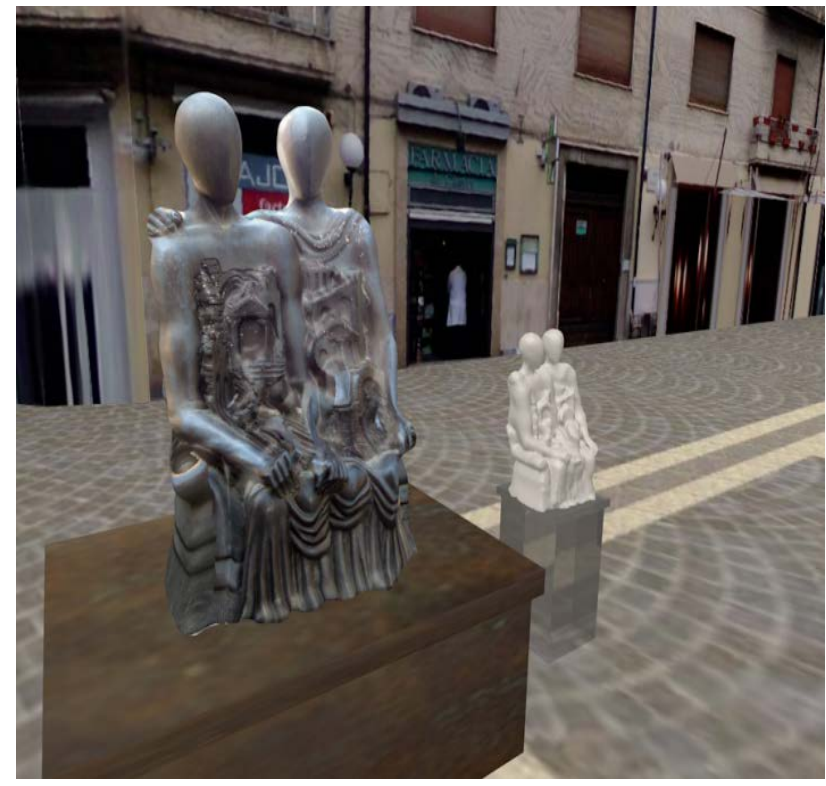

Figure 22. The models of The great archaeologists and of the miniature in the new position.

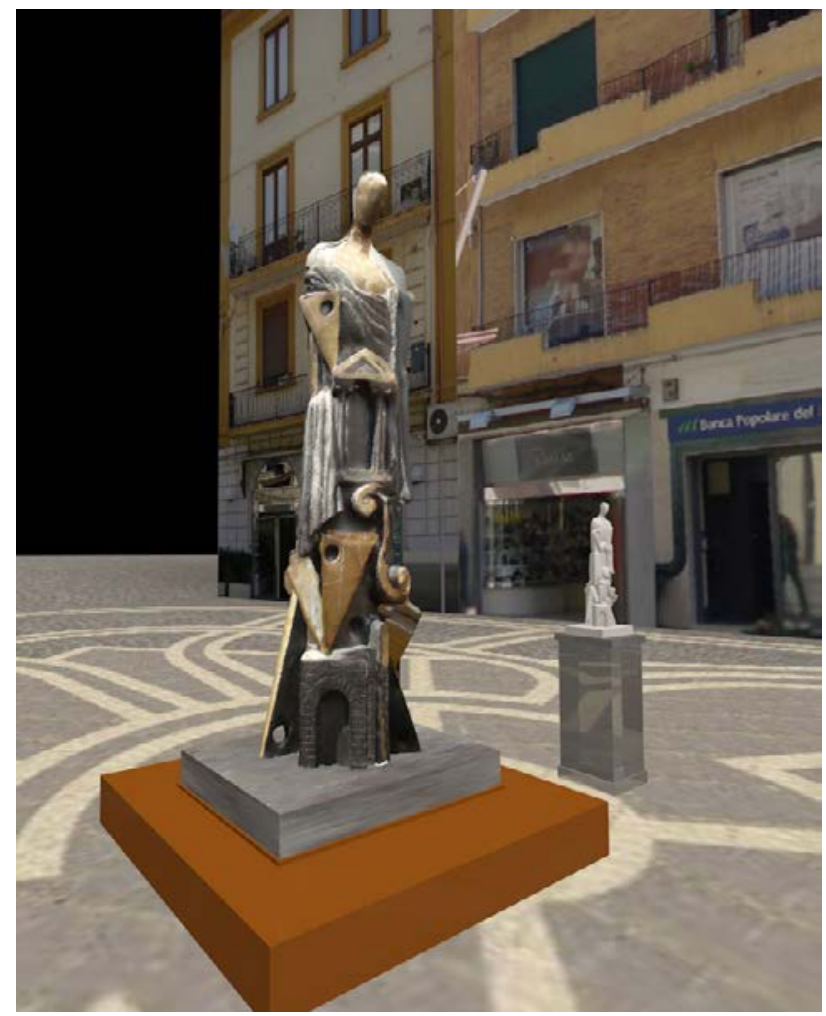

Figure 23. The model of The great Metaphysicist and of the miniature in the new position.

\section{CONCLUSIONS}

The 3D model of the MAB open air museum has been used to implement a Web-GIS allowing the citizen's participation, understanding and suggestions. The 3D city model, intended as a new tool for urban planning, has been used both for representing the current situation of the MAB and for design purposes. By acknowledging suggestions regarding a possible different location of the statues and the possibility for disabled people to enjoy the museum, a new arrangement has been designed. In the second release of the Web-GIS, two kind of users are foreseen: the normal citizens and the professionals. Different utilities and statistics will be reserved for the professionals, thus allowing more effective contributions by the stakeholders.

\section{REFERENCES}

Arnstein, S.R., 1969. A Ladder of Citizen Participation. JAIP, Vol. 35, No. 4, July 1969, pp. 216-224.

Artese G., Achilli V., Abitrante M., 2003. Dynamic 3D representation of architecture as a design tool: the old town of Cosenza. International Archives of Photogrammetry and Remote Sensing - Vol. XXXIV 5/W12 Comm. V, pp. 28-33.

Artese G., De Napoli L., Artese S., 2013. T.O.F. laser scanner for the surveying of statues: a test on a real case. International Archives of the Photogrammetry, Remote Sensing and Spatial Information Sciences, Vol. XL-5/W2, pp. 67-72.

Axford, S., Keltie, G., Wallis, C., 2007. Virtual Reality in Urban Planning and Design, in Multimedia Cartography. Springer, Berlin Heidelberg, pp. 283-294.

Beraldin J.-A., Cournoyer L., Rioux M., Blais F., El-Hakim S.F., Godin G., 1997. Object model creation from multiple range images: acquisition, calibration, model building and verification, Proc. 1st Int'l Conf. on 3-D Digital Imaging and Modeling, IEEE, 1997, pp. 326-333.

Besl P.J., McKay N.D., 1992. A Method for Registration of 3-D Shapes, IEEE Transactions on Pattern Analysis and Machine Intelligence, 14(2), pp. 239-256.

G. Burdea, P. Coiffet - Virtual Reality Technology - Sec. Edition, Wiley, Hoboken, New Jersey, USA - 2003.

Chen Y., Medioni G., 1992. Object Modeling by Registration of Multiple Range Images, Image and Vision Computing, 10(3), pp. 145-155.

El-Hakim S.F., Beraldin J.A., Picard M., Godin G., 2004. Detailed 3D reconstruction of large-scale heritage sites with integrated techniques., IEEE Computer Graphics and Application, 24(3), 21-29.

El-Hakim, S., Remondino, F., 2006. Image-Based 3d Modelling: A Review, The Photogrammetric Record 21(115): 269-291.

Gibson T., 1998. The Doer's Guide to Planning for Real, Neighbourhood Initiatives Foundation, Telford. 68 pp.

Gröger, G., Plümer, L., 2012. CityGML - Interoperable semantic 3D city models, ISPRS Journal of Photogrammetry and Remote Sensing , 71 (1) (2012), pp. 12-33.

Haala, N., Kada M., 2010. An update on automatic 3D building reconstruction, ISPRS Journal of Photogrammetry and Remote Sensing, 65 (6) (2010), pp. 570-580.

Hammoudi K., Dornaika F., 2011. A Featureless Approach to 3D Polyhedral Building Modeling from Aerial Images, Sensors 11, pp. 228-259. 
Jordanes, 552. De origine actibusque Getarum - English Version (The Origin and Deeds of the Goths) by Charles Christopher Mierow, Princeton University Press, 1908 - 100 pp.

Knapp, S., Coors, V., 2008. The use of eParticipation in public participation: The VEPs example. In: Coors, V., Rumor, M., Fendel, E.M., Zlatanova, S. (Eds.), Urban and regional data management. Proceedings of the Urban Data Management Society Symposium 2007, Stuttgart, Germany, 10-12 October. Taylor \& Francis, London, pp. 93-104.

Pasetti Monizza G., Marchesi M., Matt D.T., Krause D. and Benedetti C., 2013. Axiomatic Design in Participated Urban Planning: Potentials and Criticism, Proc. Second International Workshop on Design in Civil and Environmental Engineering, 2013, WPI - pp.39-45.

Remondino, F., Gruen, A., von Schwerin, J., Eisenbeiss, H., Rizzi, A., Girardi, S., Sauerbier, M., Richards-Rissetto, H., 2009. Multi-Sensor 3d Documentation of the Maya site Of Copan, Proceedings of 22nd CIPA Symposium, October 11-15, 2009, Kyoto, Japan.

Ressl C., 2007. Reconstruction of the Pegasus Statue on Top of the State Opera House in Vienna using Photogrammetry and Terrestrial and Close-Range Laser Scanning, Lasers in the Conservation of Artworks, Springer proceedings in physics Volume 116, pp 535-542.

Sutherland, I. E., 1965. The ultimate display. Proceedings of the International Federation of Information Processing Congress, 2,506-508, 1965.

Tian, Y., Gerke, M., Vosselman, G.M., Zhu Q., 2010. Knowledge-based building reconstruction from terrestrial video sequences. ISPRS Journal of Photogrammetry and Remote Sensing, 65 (4) (2010), pp. 395-408.

Zhang Z., 1994. Iterative Point Matching for Registration of Freeform Curves and Surfaces, International Journal of Computer Vision, 13(2), pp. 119-152.

http://www.3dreshaper.com/ (3 Mar. 2014).

http://www.geomagic.com/en/products/studio/overview

(3 Mar. 2014).

http://hds.leica-geosystems.com/en/Leica-Cyclone_6515.htm (3 Mar. 2014).

Non-Contact 3d Digitizer Vivid 300/Vi-300 Instruction Manual http://sensing.konicaminolta.us/wpcontent/uploads/2011/05/VI VID300_Hard.pdf (9 Lug. 2013).

Leica ScanStation C10 Datasheet, http://hds.leicageosystems.com/downloads123/hds/hds/ScanStation\%20C10/br ochures-datasheet/Leica_ScanStation_C10_DS_en.pdf (9 Lug. 2013).

http://www.planningforreal.org.uk/ (6 Mar. 2014). 